\title{
Solid-State Bipolar Marx Converter with Output Transformer and Energy Recovery
}

\author{
H. Canacsinh ${ }^{1,2}$, José Fernando Silva ${ }^{3,4}$, Sónia F. Pinto ${ }^{3,4}$, Luis M. Redondo ${ }^{1,2}$, \\ and João Santana ${ }^{3,4}$ \\ ${ }^{1}$ Instituto Superior de Engenharia Lisboa, ISEL/CEEI, Lisbon, Portugal \\ ${ }^{2}$ Nuclear Physics Center from Lisbon University, CFNUL, Lisbon, Portugal \\ ${ }^{3}$ Instituto Superior Técnico, TU Lisbon, 1049-001 Lisbon, Portugal \\ ${ }^{4}$ Center for Innovation in Electrical and Energy Engineering, 1049-001 Lisbon, Portugal
}

\begin{abstract}
The purpose of this paper is to present and discuss a general HV topology of the solid-state Marx modulator, for unipolar or bipolar generation connected with a step-up transformer to increase the output voltage applied to a resistive load. Due to the use of an output transformer, discussion about the reset of the transformer is made to guarantee zero average voltage applied to the primary. It is also discussed the transformer magnetizing energy recovering back to the energy storage capacitors. Simulation results for a circuit that generates $100 \mathrm{kV}$ pulses using $1000 \mathrm{~V}$ semiconductors are presented and discussed regarding the voltage and current stress on the semiconductors and result obtained.
\end{abstract}

Keywords: Bipolar high-voltage pulses, solid-state switches, high-voltage transformer, Marx converter topology, Energy recovery.

\section{Introduction}

Industries such as food sterilization and wastewater processing have demonstrated an increased interest in high-voltage pulses over the last years. Experience has shown that in most of these cases the use of bipolar pulses results in an improved process performance and in enhanced final products, compared to the obtained with the use of unipolar positive or negative pulses. This represents an additional value to the industrial method and has contributed strongly to the development of efficiency and flexibility of the bipolar high-voltage modulators [1-2].

Considering the techniques that are based on solid-state technology, a frequent method to generate high-voltage bipolar pulses includes the use of two d-c power supplies with series switches, for the positive and negative voltage, which implies the use of series stacks of semiconductors to hold-off the voltage [1,3]. Also, solid-state multilevel converters have been proposed to generate high-voltage bipolar pulses [4].

The circuit used to obtain high-voltage pulses either unipolar or bipolar is based on the Marx modulator concept. Recent technological upgrading done in the mature Marx unipolar generator concept led to the intensive use of semiconductor switches contributing to a performance increase of the original circuit [5-7]. A generalized solid-state Marx modulator with one low power supply and able to deliver repetitive unipolar or bipolar high-voltage output pulses was presented by [8], shown in Fig. 1. 
Hybrid topologies were attained with the combination of Marx generator with a step-up pulsed transformer [9]. This approach decreases the number of needed solidstate switches, reduces the turns ratio of the transformer and provides galvanic isolation to the load.

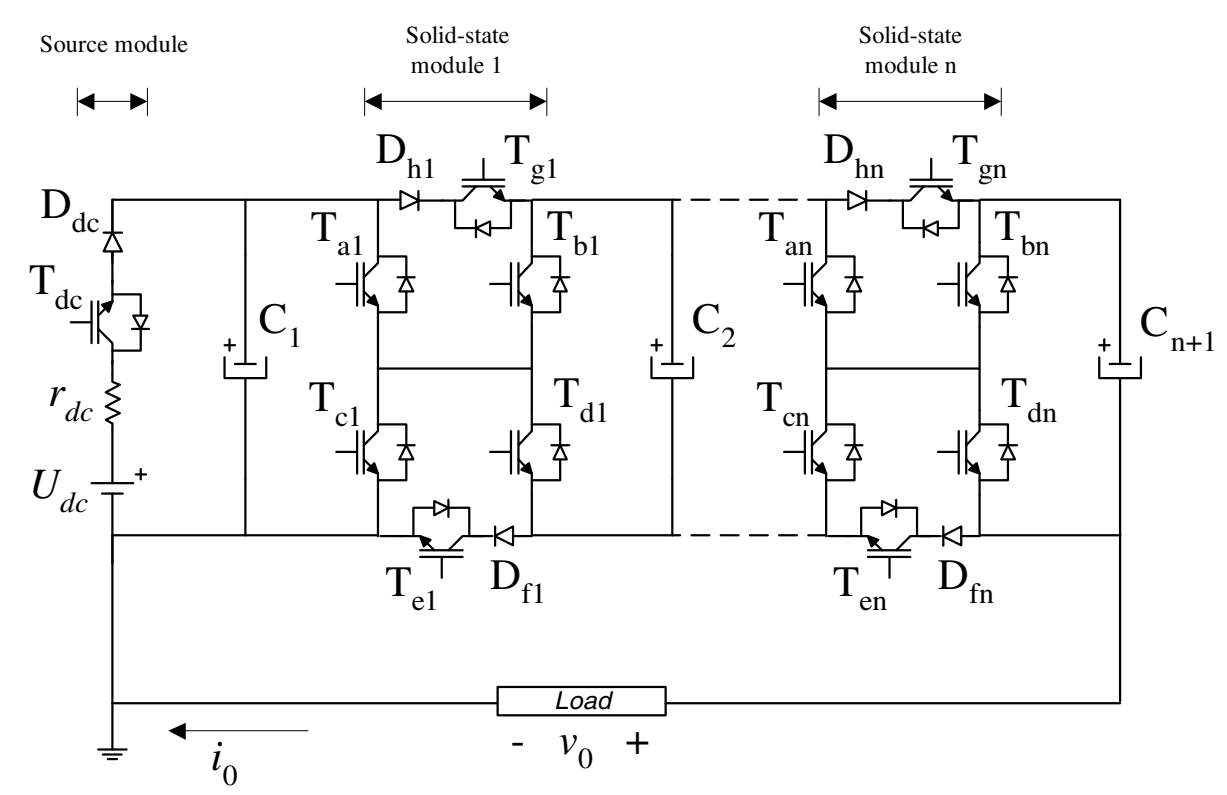

Fig. 1. General HV topology of the n stages solid-state Marx modulator, for unipolar or bipolar generation

In this work, simulated results and analysis is made regarding the connection of a pulse transformer to the Fig. 1 topology to further increase the pulse amplitude. The reset of the transformer is discussed to improve the circuit performance.

\section{Contribution to Value Creation}

The connection of a high-voltage pulsed transformer to a solid-state bipolar Marx modulator in order to further increase the voltage in a load is an innovation. If the semiconductor switches are triggered the right way it is possible to reset the transformer core between pulses, recovering this energy to the main capacitors, and at the same time decreasing the reset voltage on the transformer secondary. This will be useful to food sterilization and wastewater processing cutting costs and creating higher quality products. 


\section{Circuit Topology}

Fig. 2 presents the circuit of Fig. 1 connected to a set-up pulse transformer, aiming the increase by $\mathrm{N}_{2} / \mathrm{N}_{1}$ of the pulse voltage amplitude applied by the solid-sate bipolar Marx generator into a resistive load.

The Marx topology in Fig. 2 circuit, explained in detail in [8], can be described shortly as a circuit that generates bipolar high-voltage pulses by connecting in series a set of capacitors into a load, previously charged in parallel from a relatively low voltage $d c$ power supply, $U_{\mathrm{dc}}$. During the charging mode switches $\mathrm{T}_{\mathrm{dc}}, \mathrm{D}_{\mathrm{dc}}, \mathrm{D}_{\mathrm{hi}}, \mathrm{T}_{\mathrm{gi}}$, $\mathrm{D}_{\mathrm{fi}}$ and $\mathrm{T}_{\mathrm{ei}}$ are turned on. During this period, the on-state of the switches $\mathrm{T}_{\mathrm{ei}}$ and $\mathrm{D}_{\mathrm{fi}}$, guarantees that voltage, $v_{0}$ applied to the primary of the transformer is nearly zero volts.

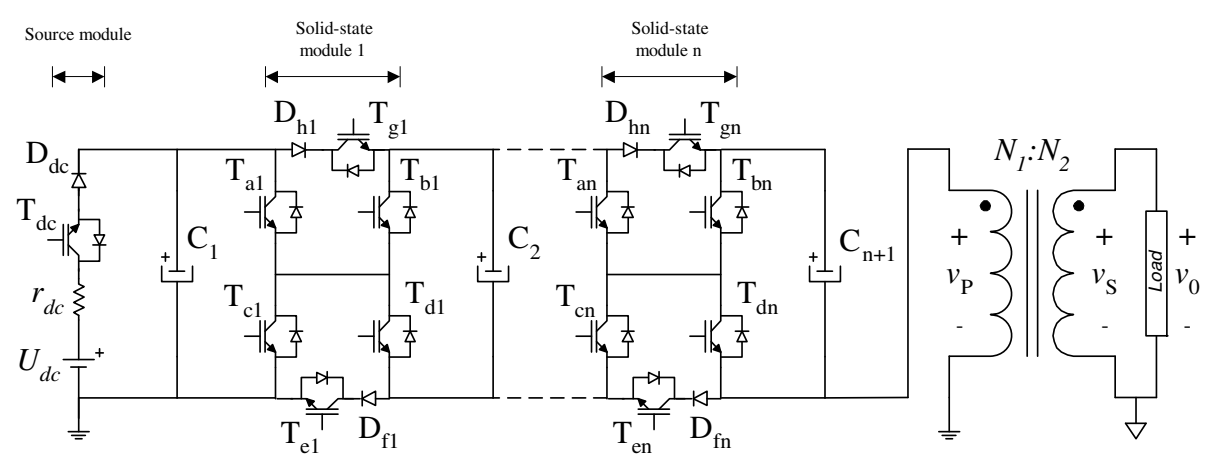

Fig. 2. Circuit of the Fig. 1 connected to a step-up transformer

The pulse mode operation can be divided in negative and positive pulses. To apply negative pulse into the load, $\mathrm{T}_{\mathrm{bi}}$ and $\mathrm{T}_{\mathrm{ci}}$ are switched on, being all the remaining switches off. During this period capacitors $\mathrm{C}_{\mathrm{i}}$ (except capacitor $\mathrm{C}_{1}$ ) are connected in series applying a voltage, for $n$ stages,

$$
v_{p}=-n U_{d c}
$$

to the transformer primary, considering all capacitor charged with $\mathrm{U}_{\mathrm{dc}}$, and a voltage

$$
v_{0}=-n U_{d c} N_{2} / N_{1}
$$

applied to the load. During this period, primary current $i_{p}$ is equal to

$$
i_{p}=i_{m}+i_{0}^{\prime}
$$

where $i_{m}$ is the magnetizing current of the transformer. Considering a linear equivalent circuit with magnetizing inductance $\mathrm{L}_{\mathrm{m}}$, it is

$$
i_{m}=v_{p} t_{p} / L_{m}
$$

where $t_{p}$ is the pulse period and $L_{m}$ the magnetizing inductance of the transformer, and $i^{\prime}{ }_{0}$ is the secondary current reduced to the primary, 


$$
i_{0}^{\prime}=i_{0} N_{2} / N_{1}
$$

being the load current given by

$$
i_{o}=v_{0} / R_{0}
$$

for a resistive load $R_{0}$.

After the negative pulse, the transformer core must be reset with and opposite voltage such that the volt-seconds product is equal to the negative pulse period voltssecond. Normally, this is achieved using auxiliary dissipative circuits where freewheeling diodes are used for speediness. The circuit presented in Fig. 2 has natural paths with diodes that accomplished this task, which consists of the IGBTs anti-parallel diodes. Moreover, these paths include the main $\mathrm{C}_{\mathrm{i}}$ capacitors whereas the reset circuit is non dissipative, besides the normal losses in the parasitic resistances of the components. Hence, after the negative pulse the magnetizing current of the transformer has a path set by freewheeling diodes $D_{c i}$ and $D_{b i}$ and capacitors $C_{i}$ (except capacitor $\mathrm{C}_{1}$ ), as shown in Fig. 3 .

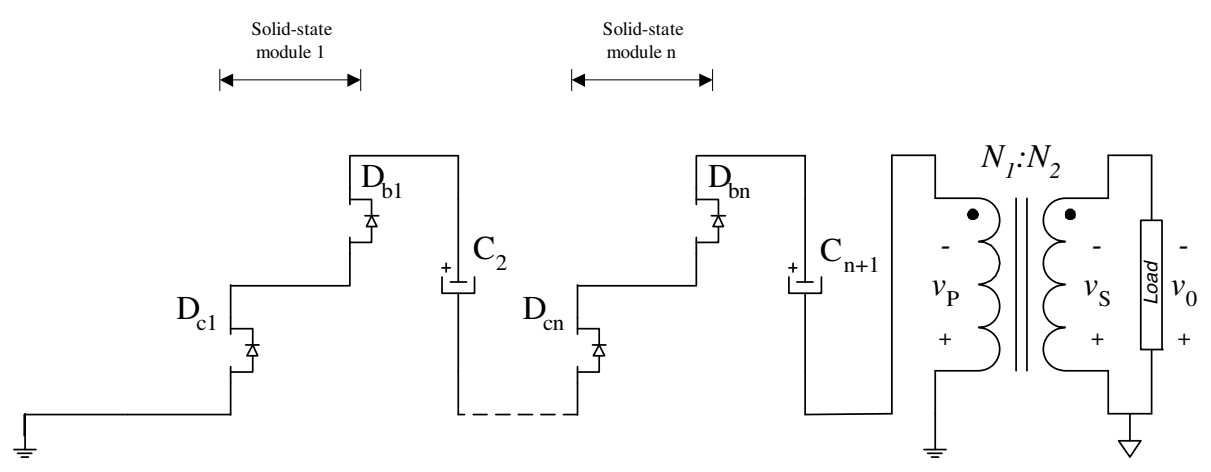

Fig. 3. Transformer reset operation mode of the circuit of Fig. 2, after negative pulse, set by freewheeling diodes $\mathrm{D}_{\mathrm{ci}}$ and $\mathrm{D}_{\mathrm{bi}}$ and capacitors $\mathrm{C}_{\mathrm{i}}$ (but capacitor $\mathrm{C}_{1}$ )

In this case, during the reset time, the transformer magnetizing energy is recovered back to the energy storage capacitors $C_{i}$ (except capacitor $C_{1}$ ), and the transformer primary is subject to an opposite polarity voltage with same magnitude of the applied pulse, which is further amplified by $\mathrm{N}_{2} / \mathrm{N}_{1}$ and applied to the load. This means that two equal amplitude pulses are successively applied to the load with opposite polarity, which is normally not desirable.

Afterwards, when the magnetizing current goes to zero the diodes go off and the reset period is over.

In order to have a lower reset voltage, it is possible to set another path for the magnetizing current to flow after the negative pulse. For example, this path can be set by freewheeling diodes $\mathrm{D}_{\mathrm{d} 1}, \mathrm{D}_{\mathrm{a} 1}, \mathrm{D}_{\mathrm{hi}}\left(\right.$ except $\mathrm{D}_{\mathrm{h} 1}$ ) and $\mathrm{T}_{\mathrm{gi}}$ (except $\mathrm{T}_{\mathrm{g} 1}$ ) and capacitor $\mathrm{C}_{\mathrm{n}+1}$, as shown in Fig. 4. Meaning that is possible to choose just one capacitor to receive the magnetizing energy. 


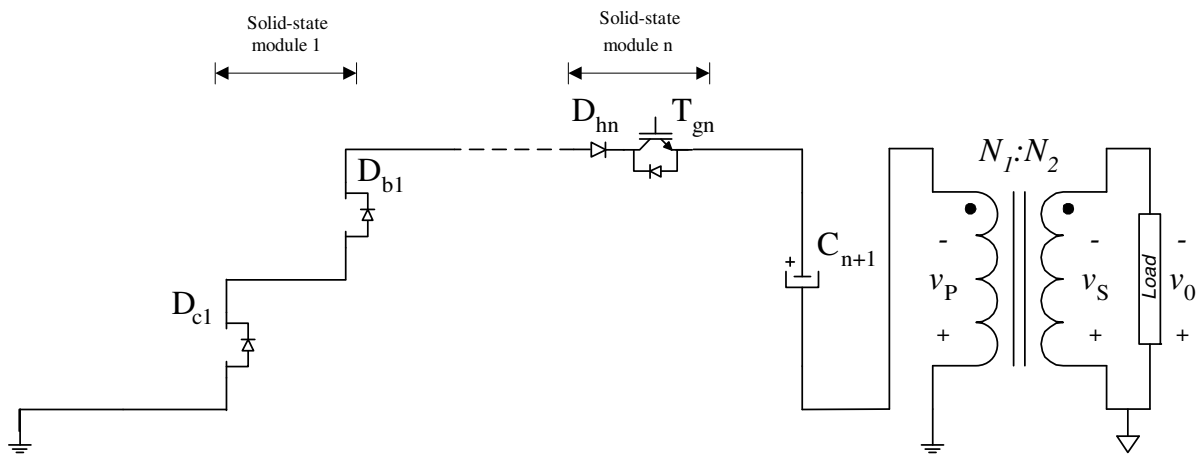

Fig. 4. Transformer reset operation mode of the circuit of Fig. 2, after negative pulse, set by freewheeling diodes $\mathrm{D}_{\mathrm{d} 1}, \mathrm{D}_{\mathrm{a} 1}, \mathrm{D}_{\mathrm{hi}}\left(\right.$ except $\mathrm{D}_{\mathrm{h} 1}$ ) and $\mathrm{T}_{\mathrm{gi}}$ (except $\mathrm{T}_{\mathrm{g} 1}$ ) and capacitor $\mathrm{C}_{\mathrm{n}+1}$, for a lower reset voltage

For the positive pulse condition the analysis is similar, being the positive pulse obtained by switching on IGBTs $\mathrm{T}_{\mathrm{ai}}$ and $\mathrm{T}_{\mathrm{di}}$, being all the remaining switches off. During this period, capacitors $\mathrm{C}_{\mathrm{i}}$ (except capacitor $\mathrm{C}_{\mathrm{n}+1}$ ) are connected in series.

The natural path to reset the transformer magnetizing energy, after the positive pulse, is set through the freewheeling diodes $D_{d i}$ and $D_{a i}$ and capacitors $C_{i}\left(C_{n+1}\right.$ is not used), as shown in Fig. 5.

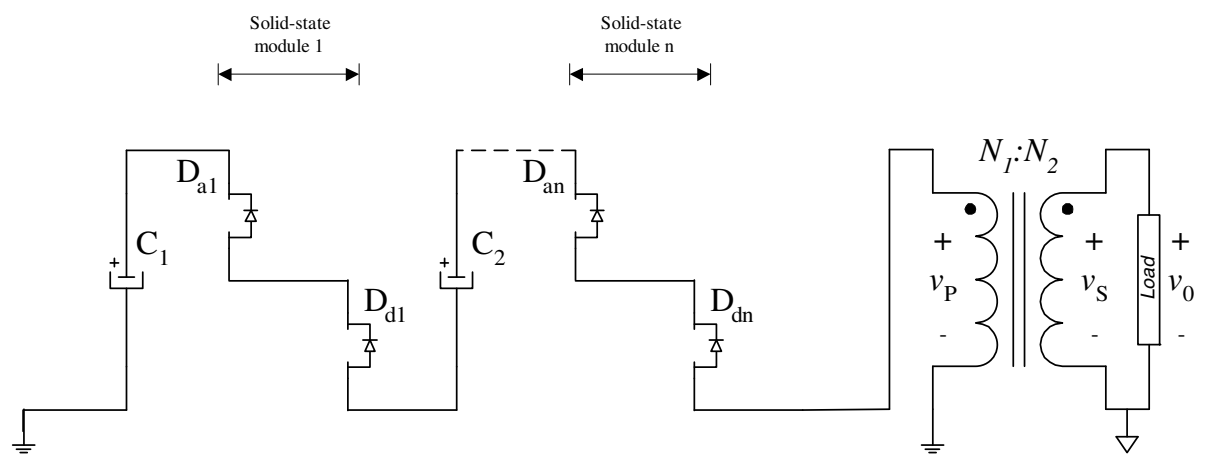

Fig. 5. Transformer reset operation mode of the circuit of Figure 2, after positive pulse, set by freewheeling diodes $\mathrm{D}_{\mathrm{di}}$ and $\mathrm{D}_{\mathrm{ai}}$ and capacitors $\mathrm{C}_{\mathrm{i}}\left(\mathrm{C}_{\mathrm{n}+1}\right.$ is not used)

Again, in reset this condition, the transformer magnetizing energy is recovered back to the energy storage capacitors $\mathrm{C}_{\mathrm{i}}$ (except $\mathrm{C}_{\mathrm{n}+1}$ ), and load withstands an opposite polarity voltage with same magnitude of the applied pulse. An alternative way is to use freewheeling diodes $\mathrm{D}_{\mathrm{dn}}, \mathrm{D}_{\mathrm{an}}, \mathrm{D}_{\mathrm{fi}}\left(\right.$ except $\mathrm{D}_{\mathrm{fn}}$ ) and $\mathrm{T}_{\mathrm{ei}}\left(\right.$ except $\left.\mathrm{T}_{\mathrm{en}}\right)$ and capacitor $\mathrm{C}_{\mathrm{n}-1}$, as shown in Fig. 6. 


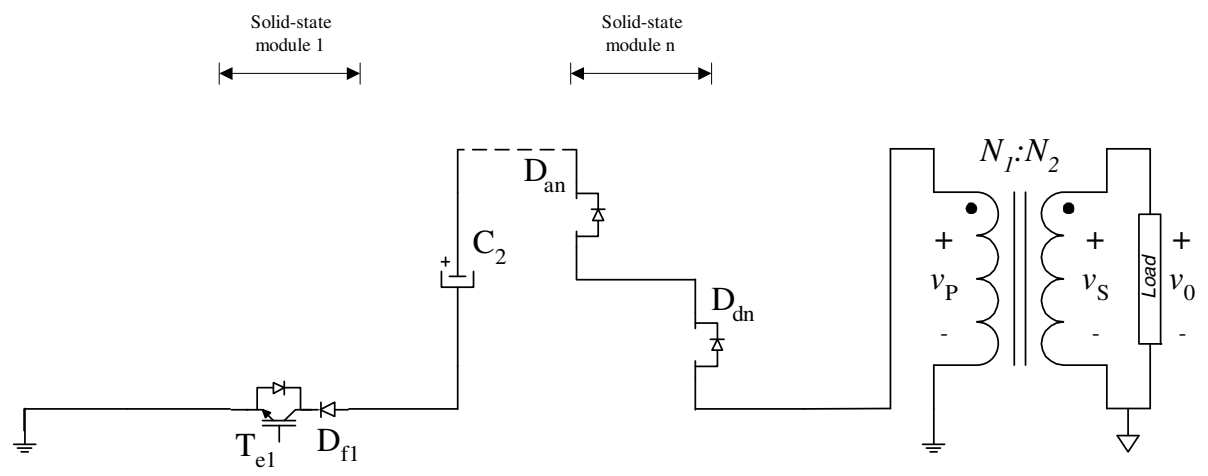

Fig. 6. Transformer reset operation mode of the circuit of Fig. 2, after positive pulse, set by freewheeling diodes $D_{d n}, D_{a n}, D_{f i}\left(\right.$ except $D_{f n}$ ) and $T_{e i}$ (except $T_{e n}$ ) and capacitor $C_{n-1}$, for a lower reset voltage

\section{Simulation Results}

In order to validate the described concept described in the last section, a simulation circuit was designed using SIMULINK/MATLAB software, containing 10 stages Marx generator operating with $U_{d c}=1000 \mathrm{~V}, \mathrm{C}_{\mathrm{i}}=1 \mu \mathrm{F}$, and a 1:10 step up transformer, AMCC - 1000, from POWERLITE Inductor Cores, with parameters presented in Table 1, capable of receiving a $10 \mathrm{kV}$ pulse in the primary and delivering a $100 \mathrm{kV}$ pulse in the secondary.

The simulated operating condition were set to $1 \%$ duty cycle with $1 \mathrm{kHz}$ repetition rate and $120 \mu$ s reset time, into a $100 \mathrm{k} \Omega$ resistive load.

Fig. 7 shows the simulated waveform for primary voltage, $v_{\mathrm{p}}$, and a primary winding pulse current, $i_{\mathrm{p}}$, into the $100 \mathrm{k} \Omega$ resistive load, using all the freewheeling diodes to reset the core with the total voltage.

Table 1. Calculated 1:10 step-up transformer parameters

\begin{tabular}{|c|c|c|c|}
\hline $\mathrm{N}_{1}$ & 43 turns & $\mathrm{R}_{1}$ & $275 \mathrm{~m} \Omega$ \\
\hline $\mathrm{N}_{2}$ & 430 turns & $\mathrm{R}_{2}$ & $28 \Omega$ \\
\hline $\mathrm{L}_{\mathrm{m}}$ & $20 \mathrm{mH}$ & $\mathrm{V}_{1}$ & $10 \mathrm{kV}$ \\
\hline $\mathrm{L}_{1}$ & $398 \mu \mathrm{H}$ & $\mathrm{V}_{2}$ & $100 \mathrm{kV}$ \\
\hline $\mathrm{L}_{2}$ & $80 \mathrm{mH}$ & & \\
\hline
\end{tabular}

It is shown in Fig. 7 that, in this situation, during the reset period (necessary to guaranty an equal volt-second balance), an opposite polarity voltage is applied into a load with the same magnitude of the pulse. This situation is not wanted as explained above. 


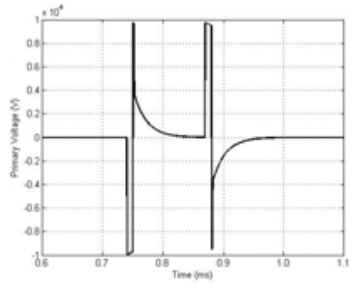

a)

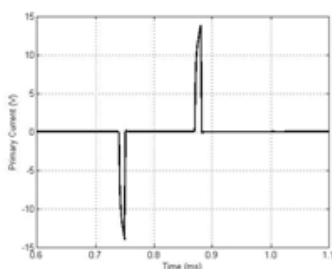

b)

Fig. 7. Simulation results for the circuit of Figure 2 with transformer reset as shown in Figures 3 and 5; horizontal scale 0.1 (ms/div), primary: a) voltage, $\left.v_{p}, 2(\mathrm{kV} / \mathrm{div}) ; \mathrm{b}\right)$ current, $i_{p}$, (5A/div)

If the condition now is set to just one capacitor being used for reset, then the results are obtained in Fig. 8. The difference in the areas of the pulse and reset period are due to energy dissipated. It can be clearly observed the two current components of the primary currents described in (3).

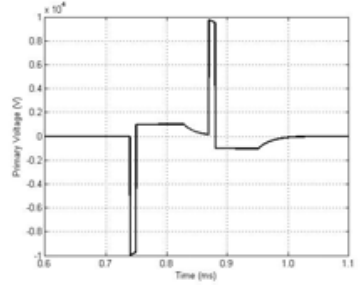

a)

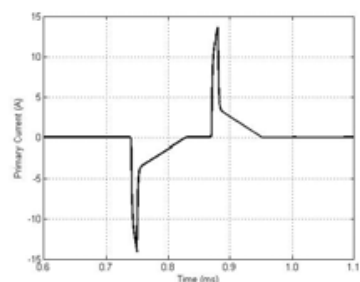

b)

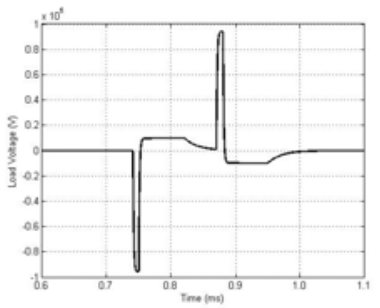

c)

Fig. 8. Simulation results for the circuit of Figure 2 with transformer reset as shown in Figures 4 and 6 ; horizontal scale 0.1 (ms/div): a) primary voltage, $\left.v_{p}, 2(\mathrm{kV} / \mathrm{div}) ; \mathrm{b}\right)$ primary current, $i_{p}$, $(5 \mathrm{~A} / \mathrm{div}) ; \mathrm{c})$ secondary voltage, $v_{0}, 20(\mathrm{kV} / \mathrm{div})$

Observing Fig. 8b), the slope of the magnetizing current decreases from its maximum value to zero during the reset of the transformer. As described above, this current is redirected to the capacitors, recovering the magnetizing energy. Fig. 8c) shows the voltage in the secondary of the transformer.

The amplitude of the reset voltage in Fig. 8 is nearly the voltage of the power supply, $1000 \mathrm{~V}$, so the reset time is longer than in Fig. 7. 


\section{Conclusions}

A hybrid integrated solid-state bipolar Marx generator circuit was presented, which associates the advantage of the intensive use of power semiconductor switches to increase the performance of the classical Marx circuit and the advantage of the topology being capable to connect an output transformer to further increase the output voltage. The Marx type bipolar topology used has the ability of recovering the transformer magnetizing energy, during the pulse off-state, back to the energy storage capacitors.

Simulation results showed 10 stages Marx circuit using $1 \mathrm{kV}$ per stage, operating with $1 \mathrm{kHz}$ repetition rate and $1 \%$ duty cycle, with a 1:10 step-up, giving $100 \mathrm{kV}$ bipolar pulses at the load and resetting the transformer with $\mathrm{U}_{\mathrm{dc}}$ after each pulse, recovering the energy to one main capacitor.

\section{References}

1. Gaudreau, M.P.J., Hawkey, T., Petry, J., Kempkes, M.: Pulsed Power systems for Food and Wastewater processing. In: Twenty Third International Power Modulator Symposium, Rancho Mirage (1998)

2. Keith, W.D., Pringle, D., Rice, P., Birke, P.V.: Distributed Magnetic Coupling Synchronizes a Staked 25-kV Mosfet Switch. IEEE Transactions on Power Electronics 15(1), 58-61 (2000)

3. Wang, C., Zhang, Q.H., Streaker, C.: A $12 \mathrm{kV}$ solid state high voltage pulse generator for a bench top PEF machine. In: IEEE Power Electronics and Motion Control Conference, Beijing, China, August 15-18, vol. 3, pp. 1347-1352 (2000)

4. Petkovsek, M., Zajec, P., Nastran, J., Voncina, D.: Multilevel bipolar high voltage pulse source - Interlock dead time reduction. In: EUROCON-Computer as a Tool, Slovenia, vol. 2, pp. 240-243 (2003)

5. Cassel, R.L.: A Solid State High Voltage Pulse Modulator which is Compact and without oil or pulse transformer. In: Power Modulator Conf., San Francisco, CA (2004)

6. Redondo, L.M., Silva, J.F., Tavares, P., Margato, E.: All Silicon Marx-bank topology for high-voltage, high-frequency rectangular pulses. In: Proceedings of the IEEE 36th Annual Power Electronics Specialists Conference, Recife, pp. 1170-1174 (2005)

7. Kim, J.H., Ryu, M.H., Min, B.D., Shenderey, S.V., Kim, J.S., Rim, G.H.: High voltage pulse power supply using Marx generator \& solid-state switches. In: 31st IEEE IECON Annual Conference (2005)

8. Redondo, L.M., Canacsinh, H., Silva, J.F.: Generalized Solid-State Marx Modulator Topology. IEEE Transactions on Dielectrics and Electrical Insulation, 16(4), 1037-1042 (2009)

9. Redondo, L.M., Silva, J.F., Tavares, P., Margato, E.: Solid-state Marx Generator Design with an Energy Recovery Reset Circuit for Output Transformer Association. In: Proceedings of the IEEE Power Electronics Specialists Conference, pp. 2987-2991 (2007) 